\title{
The Expression of Sphingosine Kinase-1 in Head and Neck Carcinoma
}

\author{
María M. Facchinetti ${ }^{a}$ Norberto A. Gandini ${ }^{a}$ María E. Fermento ${ }^{a}$ \\ Norma B. Sterin-Speziale ${ }^{c}$ Youngmi Ji $^{d}$ Vyomesh Patel $^{\mathrm{e}} \quad$ J. Silvio Gutkind ${ }^{\mathrm{e}}$ \\ Maria G. Rivadullab Alejandro C. Curino ${ }^{a}$ \\ a Laboratorio de Biología Básica del Cáncer, Instituto de Investigaciones Bioquímicas Bahía Blanca, \\ INIBIBB-CONICET and b Servicio de Patología del Hospital Municipal Dr Leónidas Lucero, Bahía Blanca, and \\ 'Laboratorio de Biología Celular e Histología, Facultad de Farmacia y Bioquímica, UBA, Buenos Aires, Argentina; \\ ${ }^{\mathrm{d}}$ Department of Surgery, Uniformed Services University of the Health Sciences and ${ }^{\mathrm{e}}$ Oral and Pharyngeal Cancer \\ Branch, National Institute of Dental and Craniofacial Research, National Institutes of Health, Bethesda, Md., USA
}

\section{Key Words}

Sphingosine kinase $\cdot$ Oral cancer $\cdot$ Sphingolipids $\cdot$ Tissue microarray

\begin{abstract}
Sphingosine kinase-1 (SPHK1) modulates the proliferation, apoptosis and differentiation of keratinocytes through the regulation of ceramide and sphingosine-1-phosphate levels. However, studies on the expression of SPHK1 in human head and neck squamous cell carcinoma (HNSCC) specimens are lacking. Therefore, the aim of the present work was to evaluate SPHK1 expression in human primary HNSCCs and to correlate the results with clinical and anatomopathological parameters. We investigated the expression of this protein by immunohistochemistry performed in tissue microarrays of HNSCC and in an independent cohort of 37 paraffin-embedded specimens. SPHK1 expression was further validated by real-time PCR performed on laser capture-microdissected tissue samples. The positive rate of SPHK1 protein in the cancerous tissues was significantly higher (74\%) than that in the
\end{abstract}

M.M.F. and N.A.G. contributed equally to this work. nontumor oral tissues (23\%), and malignant tissues showed stronger immunoreactivity for SPHK1 than normal matching samples. These results were confirmed by real-time PCR quantification of SPHK1 mRNA. Interestingly, the positive expression of SPHK1 was associated with shorter patient survival time (Kaplan-Meier survival curves) and with the loss of p21 expression. Taken together, these results demonstrate that SPHK1 is upregulated in HNSCC and provide clues of the role SPHK1 might play in tumor progression.

Copyright $\odot 2010$ S. Karger AG, Basel

\begin{tabular}{ll} 
Abbreviations used in this paper \\
\hline HNSCC & head and neck squamous cell carcinoma \\
IHC & immunohistochemistry \\
IRS & immunoreactive score \\
LCM & laser capture microdissection \\
OSCC & oral squamous cell carcinoma \\
qRT-PCR & quantitative real-time PCR \\
SCC & squamous cell carcinoma \\
SPHK & sphingosine kinase \\
S1P & sphingosine-1-phosphate \\
TMA & tissue microarray
\end{tabular}

Dr. Alejandro C. Curino

Laboratorio de Biología Básica del Cáncer, Instituto de Investigaciones Bioquímicas Bahía Blanca (INIBIBB), Centro Científico Tecnológico Bahía Blanca Camino La Carrindanga Km 7 - C.C. 857, 8000 Bahía Blanca (Argentina)

Tel. +54 291486 1201, ext. 118, Fax +54 291486 1200, E-Mail acurino@ criba.edu.ar 


\section{Introduction}

Head and neck squamous cell carcinomas (HNSCCs) are among the most aggressive types of cancers. Despite emerging new surgical techniques and chemoradiation protocols, HNSCC remains among the five leading causes of solid tumor-related deaths in the United States and the fourth most prevalent cancer among men worldwide [Jemal et al., 2004 and 2007]. The prognosis of HNSCC patients is relatively poor, largely due to the advanced nature of the disease at the time of diagnosis. Although several tissue biomarkers, such as cyclin D1, p53, p16, cyclo-oxygenase-2, vascular endothelial growth factor, epidermal growth factor receptor and matrix metalloproteinases, have been associated with HNSCC, there is still a need for new diagnostic and/or prognostic markers.

Sphingolipids regulate various aspects of cell survival, cell growth, cell proliferation and programmed cell death [Hait et al., 2006; Hannun et al., 2008]. In particular, the bioactive sphingolipids ceramide, sphingosine and sphingosine-1-phosphate (S1P) exert different effects on cells. Although ceramide and sphingosine have been shown to promote apoptosis and induce growth arrest, S1P on the other hand has been demonstrated to prevent apoptosis and stimulate cellular proliferation [Futerman et al., 2004; Alvarez et al., 2007]. The balance of these important lipid signal molecules is critically regulated by sphingosine kinase (SPHK) of which two isoforms have been cloned and characterized to date [Kohama et al., 1998; Liu et al., 2000; Pitson et al., 2000]. Whereas SPHK1 has been associated with promoting cell growth, protecting cells against apoptosis, inducing cell transformation and facilitating angiogenesis [Olivera et al., 1999; Xia et al., 2000; Hla et al., 2003; Kohno et al., 2006; Vadas et al., 2008], SPHK2 has been implicated in arresting cell growth and promoting apoptosis [Igarashi et al., 2003; Liu et al., 2003; Spiegel and Milstien, 2007]. The functional role of SPHK2 in cancer is much less characterized than that of SPHK1.

SPHK1, on the other hand, has been extensively studied; for instance, mRNA levels of SPHK1 have been shown to be upregulated in a variety of solid tumors, including breast, colon, lung, ovary, prostate, stomach and uterus [Murate et al., 2001; Vadas et al., 2008]. Similarly, the SPHK1 protein was found to be upregulated in lung cancer as detected in samples of normal tissue compared with non-small cell cancer tissue in patients [Johnson et al., 2005]. Other reports correlated SPHK1 expression with poor prognosis in glioblastoma [Van Brocklyn et al., 2005] as well as breast cancer [Ruckhaberle et al., 2007]

The Expression of SPHK1 in Head and Neck Carcinoma and with tumor stage in colon cancer [Kawamori et al., 2006]. Overwhelming evidence suggests that in every type of cancer examined so far, there is increased expression of SPHK1, which can contribute to drug resistance in some cases [Shida et al., 2008; Vadas et al., 2008].

Interestingly, SPHK1 has been shown to modulate proliferation and differentiation [Herzinger et al., 2007; Hong et al., 2008; Schuppel et al., 2008] and to exert antiapoptotic effects [Hammer et al., 2004] in keratinocytes through the action of its lipid product S1P. However, there is little evidence of the role that SPHK1 plays in HNSCC. In this regard, it has been previously reported that phenoxodiol, a potent inhibitor of activated SPHK1 [Gamble et al, 2006; Vadas et al., 2008], induces cell cycle arrest in HNSCC cell lines by upregulation of p21 [Aguero et al., 2005], although a direct effect of phenoxodiol on SPHK1 was not demonstrated. Therefore, the aim of our study was to investigate the expression of SPHK1 and its correlation with clinical and anatomopathological parameters in a panel of human HNSCCs representing different histological grades using immunohistochemistry (IHC) and quantitative real-time PCR (qRT-PCR) of laser capture-microdissected tumor tissue samples.

\section{Materials and Methods}

\section{Tissue Specimens}

Tissue microarrays (TMAs) were constructed by the Head and Neck Cancer Tissue Array Initiative, Oral and Pharyngeal Cancer Branch, National Institute of Dental and Craniofacial Research, National Institutes of Health [Molinolo et al., 2007] with IRB approval. Two different array blocks were used; one included tissues procured from North and South America and South Africa, and the other block included tissues from Southeast Asian countries. Both blocks included a total of 246 HNSCC cases with varying degrees of differentiation. The vast majority of the cases of known origin corresponded to squamous cell carcinomas that originated in the oral mucosa (153) and 93 to extraoral HNSCC (pharynx, larynx and other locations). Additionally, 45 cores of nonmalignant tissues including oral tissues $(\mathrm{n}=13$; floor of the mouth, tongue, gingiva and palate) and several other tissues $(n=32$; breast, placenta, colon, salivary glands, liver, lymph node, lung and skin) were included as controls. Data on the initial diagnosis, site, staging, age, sex, recurrence and survival were collected. The distribution of cases based on their differentiation was similar across countries without any significant differences; approximately $40 \%$ of the cases were well-differentiated carcinomas, $37 \%$ were moderately differentiated and $23 \%$ were poorly differentiated. Three TMA slides of each array block were used for SPHK1 and 2 slides for $\mathrm{p} 21^{\mathrm{WAF} 1 / \mathrm{CIP} 1}$ and $\mathrm{p} 53$ immunostaining.

Additionally, a cohort of 37 independent tissue samples of HNSCC was analyzed in this retrospective study. These samples were retrieved from the Pathology Service of the Bahía Blanca Regional Hospital with IRB approval and were staged according 
to the American Joint Committee on Cancer staging system [Greene et al., 2002]. They belonged to patients who had undergone surgical treatment between April 1998 and May 2004. Clinical follow-up was available up to May 2008 or until the patient's death, and additional key information, such as the occurrence of metastasis and/or local recurrence, was recorded and available. These samples were hyperplastic epithelium $(n=1)$, well-differentiated (WD; $n=3)$, moderately differentiated $(M D ; n=18)$ and poorly differentiated (PD; $\mathrm{n}=15$ ) stage II and III oral squamous cell carcinomas. Samples from patients who had received either chemo- or radiotherapy before surgery were excluded. In total, there were 31 samples from males and 6 from females with a median age of 61 (range 27-81). Paraffin blocks were available, and hematoxylin and eosin-stained slides were performed and further re-evaluated by a pathologist (M.R.). The quality of each section was assessed, and then certain slides were selected for quantitative evaluation based on successful fixation, proper orientation, and the presence of representative lesions. A series of $5-\mu \mathrm{m}$ sections were cut from each sample and transferred onto polarized histological glass slides for further analysis.

\section{Immunohistochemistry}

Slides were deparaffinized in xylene and rehydrated in a series of ethanol dilutions (100, 95 and 70\%) and water. They were incubated for $10 \mathrm{~min}$ in $3 \%$ hydrogen peroxide to quench endogenous peroxidase. After washing in PBS, sections were blocked for 30 min in 2\% BSA in PBS (blocking solution). Sections were then incubated overnight at $4^{\circ} \mathrm{C}$ with either primary rabbit anti-hSPHK1 antibody (4 $\mu \mathrm{g} / \mathrm{ml}$ in blocking solution), rabbit anti-p53 (FL393, 1:100; Santa Cruz Biotechnology) or mouse p21 WAF1/CIP1 (1:100; Beckton Dickinson), followed by 60 -min incubation with diluted biotinylated secondary antibody and then 30-min incubation with VECTASTAIN ABC Reagent (Vector Laboratories Inc.). The anti-hSPHK1 antibody was prepared by the Medical University of South Carolina Antibody Facility as described previously [Johnson et al., 2002]. Briefly, a synthetic oligopeptide corresponding to the last 20 amino acids of the C-terminal (CVEPPPSWKPQQMPPPEEPL) of the hSPHK1 (GenBankTM accession No. AAF73423) was conjugated to keyhole limpet hemocyanin and injected into New Zealand white rabbits. Antiserum was affinity purified over a cyanogen bromide-activated agarose column bound with the same oligopeptide and eluted with $100 \mathrm{~mm}$ glycine ( $\mathrm{pH}$ 2.5). For negative controls, the primary antibodies were replaced with isotype-specific IgG. Diaminobenzidine $/ \mathrm{H}_{2} \mathrm{O}_{2}$ was used as a substrate for the immunoperoxidase reaction, and slides were developed for $4 \mathrm{~min}$ for SPHK1 and $6 \mathrm{~min}$ for p53 and p21. They were lightly counterstained with hematoxylin, dehydrated through graded ethanol and xylene, and mounted with Permount (Fisher Scientific) for analysis by bright-field microscopy.

\section{Evaluation of Staining Intensity and Statistical Analysis}

All samples were evaluated and scored simultaneously by a pathologist (M.R.) and two graduate students (M.F. and A.G.). The specimens were assessed using the semi-quantitative immunoreactive score (IRS). The IRS was calculated by multiplying the staining intensity (graded as: $0=$ no, $1=$ weak, $2=$ moderate and $3=$ strong staining) and the percentage of positively stained cells ( $0=$ less than $10 \%$ of stained cells, $1=11-50 \%$ of stained cells, $2=51-80 \%$ of stained cells and $3=$ more than $81 \%$ of stained cells). The mean IRS for SPHK1 in 10 randomly chosen fields of the individual IHC (400× magnification) was determined. In the TMA, only representative tissue cores containing at least 200 tumor cells were scored. Sections with an IRS $>0$ were considered positive. The SPHK1 staining grade was divided into three groups: negative (IRS 0), low staining (IRS 1-3) and high staining (IRS 4-9) (fig. 2a). For scoring p53 immunoreactivity, the criteria by Gorgoulis et al. [1995] were adopted. p53 was considered to be overexpressed when more than $10 \%$ positive nuclear staining was observed. For p $21^{\mathrm{WAF} 1 / \mathrm{CIP} 1}$, less than $50 \%$ nuclear staining was considered loss of expression [Bukholm et al., 1997].

All scores were entered into a standardized electronic spreadsheet (Excel for Microsoft Windows). The statistical significance of SPHK1 expression levels between groups was determined by the two-tailed Mann-Whitney U test. The Spearman correlation test was used to study associations between the expression levels of p53 or p21 and SPHK1. Survival intervals were measured from the time of surgery to death from disease or until the last followup. Overall survival according to SPHK1 expression was constructed using Kaplan-Meier survival curves, and the log-rank test was used for comparison of survival curves in univariate analyses. For this, a subgroup of male patients with stage III oral squamous cell carcinoma (OSCC) was selected $(n=22)$. All received the same treatment after surgery. All analyses were performed using SPSS 14 (SPSS Inc., Chicago, Ill., USA). p values of less than 0.05 indicated a significant result.

\section{Protein Extraction and Immunoblot Analysis}

$\mathrm{HaCaT}$ cells were cultured in DMEM growth media to $70 \%$ confluence. Transient expression of pcDNA3-SPHK1 [Johnson et al., 2002] was accomplished using Lipofectamine 2000 (Invitrogen, Carlsbad, Calif., USA) according to the manufacturer's protocol. Immunoblotting was performed as described previously [Facchinetti et al., 2004]. Briefly, $50 \mu \mathrm{g}$ of protein was electrophoretically resolved by SDS-PAGE and transferred onto a polyvinylidene difluoride membrane Immobilon-P (Millipore, Bedford, Mass., USA). Blots were incubated with the same SPHK1 polyclonal antibody used for IHC $(0.6 \mu \mathrm{g} / \mathrm{ml}$ in PBS), and reactions were detected by horseradish peroxidase-conjugated secondary antibodies and enhanced chemiluminescence, following the manufacturer's directions (Pierce, Rockford, Ill., USA). Horseradish peroxidase-conjugated anti-rabbit antiserum $(1: 5,000)$ was purchased from Amersham Biosciences (Arlington Heights, Ill., USA).

\section{Laser Capture Microdissection}

Slides containing frozen tissue sections belonging to 4 OSCC patients were fixed in 70\% ethanol (30 s); after washing in $\mathrm{ddH}_{2} \mathrm{O}$, these were stained very briefly in Mayer's hematoxylin (10-15 s), followed by dehydration through graded ethanol (70-100\%) and Safeclear II (xylene substitute; Fisher Diagnostics, Middletown, Va., USA). For laser capture microdissection (LCM), stained uncovered slides that were thoroughly air dried were used. After locating the cells of interest, a CapSure LCM Cap (MDS Analytical Technologies, Mountain View, Calif., USA) was placed over the target area and pulsed with laser to adhere cells to the cap; after sufficient capture (500-1,000 cells), the cap was transferred to a $0.5-\mathrm{ml}$ sterile microfuge tube containing RNA extraction buffer (Stratagene RNA Micro-Isolation Kit; Stratagene) for immediate processing, following the protocol provided by the manufacturer. 


\section{RNA Amplification}

Total RNA extracted from 500-1,000 cells (10-50 ng) underwent two rounds of amplification using the MessageAmp II aRNA Amplification Kit (Applied Biosystems, Austin, Tex., USA), following the protocol provided. Briefly, each sample was reverse transcribed with T7-oligo(dT) as the anchoring primer. After synthesis of the second strand, the resulting cDNA underwent purification, which was subsequently used as template for in vitro transcription using T7 polymerase to produce the first-round aRNA. After purification, the resulting aRNA (300-500 ng) underwent an additional round of amplification to modify and prepare the product for downstream gene expression analysis. Essentially, this modification involved reverse transcription with T3N9 $(1 \mu \mathrm{g} / \mu \mathrm{l})$ anchoring primers and the in vitro transcription reaction with T3 polymerase, and collectively, this resulted in an approximate 10,000-fold increase in the aRNA for most samples.

\section{Quantitative Real-Time PCR}

The expression of the selected protein was confirmed by qRTPCR analysis. Briefly, $1 \mu \mathrm{g}$ of aRNA, isolated and amplified as described above, was used as starting material, to which 1 microliter $(3 \mu \mathrm{g} / \mu \mathrm{l})$ of random primers and DEPC-treated water were added for a total volume of $25 \mu$. The RNA mix was heated at $65^{\circ} \mathrm{C}$ for $5 \mathrm{~min}$ and then chilled on ice. The other components were added to each RNA mix as follows: $10 \mu l$ of $5 \times$ first-strand buffer, $5 \mu \mathrm{l}$ of $0.1 \mathrm{M} \mathrm{DTT}, 1 \mu \mathrm{l}$ of $25 \mathrm{mM}$ dNTPs, $1 \mu \mathrm{l}$ of ribonuclease inhibitor and $6 \mu \mathrm{l}$ of DEPC-treated water. The samples were incubated at $42^{\circ} \mathrm{C}$ for $2 \mathrm{~min}$, followed by the addition of $1 \mu \mathrm{l}$ of Superscript II (40 U/ $\mu$ l; Invitrogen), and incubated at $42^{\circ} \mathrm{C}$ for 50 min. The reaction was inactivated at $70^{\circ} \mathrm{C}$ for $5 \mathrm{~min}$, followed by the addition of $1 \mu \mathrm{l}(2 \mathrm{U} / \mu \mathrm{l})$ of RNAse $\mathrm{H}$ and incubation at $37^{\circ} \mathrm{C}$ for $20 \mathrm{~min}$. The resulting cDNA was used as a substrate for qRTPCR reactions, which were performed in the Bio-Rad iCycler, using Gene Expression Analysis software and IQ SYBR Green Supermix (Bio-Rad Laboratories, Hercules, Calif., USA) with a specific gene primer set (see below) according to the manufacturer's instruction. To assess relative gene expression, the $2^{-\Delta \Delta \mathrm{Ct}}$ method of relative quantification [Livak et al., 2001] was applied. HPRT was used to normalize the quantitative data.

SPHK1: F-AAGACCTCCTGACCAACTGC, R-GGCTGAGCACAGAGAAGAGG

HPRT: F-TGGACAGGACTGAACGTCTTG, R-CCAGCAGGTCAGCAAAGAATTTA

\section{Results}

\section{Validation of Antibody and SPHK1 Expression in} HNSCC

Immunospecificity of the antibody for human SPHK1 had been previously tested by immunoblot and IHC analysis and confirmed by immunoabsorption using the synthetic oligopeptide that the antibody was developed against [Johnson et al., 2002, 2005]. To further validate the use of the antibody for detection of SPHK1 in HNSCC, we first performed Western blot of protein lysates of human epidermal keratinocytes (HaCaT; fig. 1a).
The antibody exclusively recognized one band representing a protein with the molecular weight of SPHK1 (42 $\mathrm{kDa}$ ). Endogenous SPHK1 levels were low (lane 1); the overexpression of SPHK1 in these cells was used as a positive control (lane 2).

We also analyzed tissue staining patterns by immunohistochemical evaluation of serial sections from human tumors. In total, 37 individual paraffin blocks of HNSCCs were assessed for SPHK1 protein expression. Material analyzed included tongue (26), gingiva (4), floor of the mouth (4), larynx (2) and oropharynx (1). This analysis showed that the antibody displayed strong staining in tumor epithelial cells (see representative IHC in fig. 1b) compared with no staining when the primary antibody was substituted with a nonimmune, isotypematched IgG (fig. 1c). Adjacent noncancerous tissue showed low SPHK1 staining (fig. 1d). We used rat kidney cortex as a positive control (fig. le, black arrow) because SPHK1 is highly expressed in the basal area of kidney proximal tubule cells [Facchinetti et al., 2008]. The immunostaining of SPHK1 disclosed strong punctated cytoplasmic staining in tumor cells (fig. 1f, black arrows), whereas connective tissue was devoid of SPHK1 staining. Seventy-five percent (28) of tumor samples stained positively for SPHK1 with strong staining (IRS >3) observed in $36 \%$ of specimens $(10)$ and low staining (IRS <3) in $64 \%$ of samples (18). SPHK1 staining was significantly increased in cancer cells compared with adjacent nonmalignant epithelia with a mean IRS of 3.8 (range 0-6) for tumors versus a mean IRS of 1.3 (range $0-2$ ) for adjacent tissue $(\mathrm{p}=0.001)$.

Taken together, this analysis showed that SPHK1 could be specifically detected by IHC in paraffin-embedded, archived HNSCC tissues and by Western blot in a keratinocyte cell line ( $\mathrm{HaCaT})$. This antibody was used for further studies of SPHK1 expression, and staining of serial sections with isotype-matched nonimmune antibodies was included as a negative control in all sections analyzed.

\section{Screening of SPHK1 Expression in HNSCC TMAs}

To screen widely for SPHK1 expression in human HNSCC samples, we performed SPHK1 immunostaining on TMAs consisting of HNSCC samples from 8 different countries (Head and Neck Cancer Tissue Array Initiative). The successfully analyzed combined material included OSCC $(\mathrm{n}=153)$ and squamous cell carcinoma from the pharynx, larynx and other locations (extraoral squamous cell carcinoma; $\mathrm{n}=93$ ). The successfully analyzed nonmalignant oral tissues included tongue $(n=7)$, 


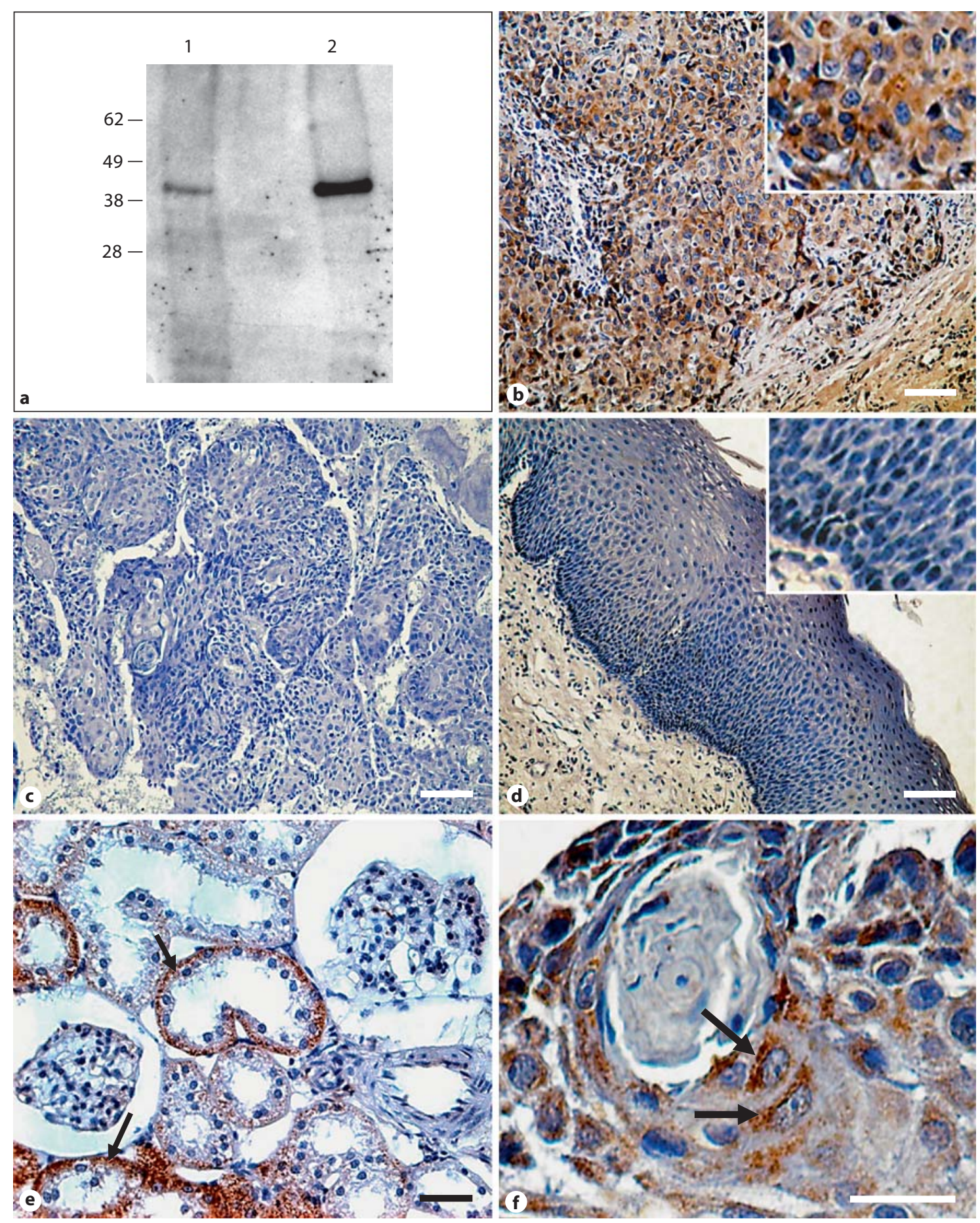

Fig. 1. SPHK1 antibody specificity and expression in HNSCC. a HaCaT cells expressing basal levels of SPHK1 (lane 1) or overexpressing SPHK1 (lane 2) were lysed and immunoblotted against SPHK1 as explained in the Methods section. The electrophoretic mobilities of marker proteins are indicated to the left. b-f IHC for SPHK1 on paraffin-embedded HNSCC human samples. Immunoreactions of SPHK1 protein expression in the cancerous tissues (b) and adjacent non-malignant epithelia (d) from oral squamous cell carcinoma patients. Kidney cortex was used as a positive control (e), and a serial section incubated with isotype-matched antibody was used as a negative control (c). f SPHK1-punctated cytoplasmic staining in cancer cells. Insets: amplification showing low SPHK1 staining in nonmalignant epithelial cells (d) or strong cytoplasmic SPHK1 staining in squamous cell carcinoma cells (b). b-e Scale bars $=100 \mu \mathrm{m}$. f Scale bar $=25 \mu \mathrm{m}$. 

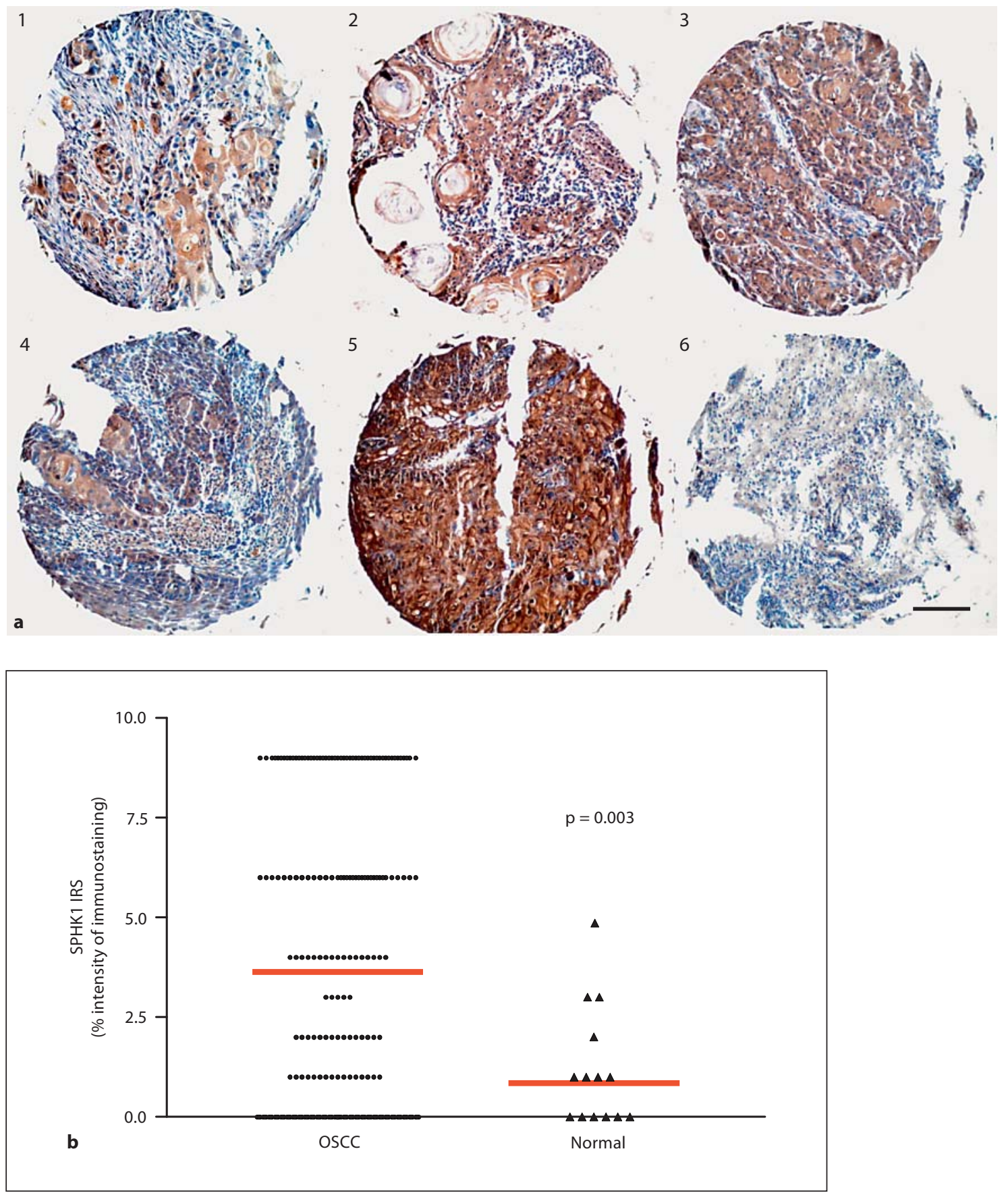

Fig. 2. Screening of SPHK1 expression in head and neck TMAs. TMA slides were immunostained with SPHK1 antibody, and immunostaining was evaluated semi-quantitatively as described in the Methods section. a Representative TMA cores showing different levels of expression of the protein are included [IRS ranging from 0 (core 6) to 9 (core 5)]. b Immunohistochemical evaluation of SPHK1 expression according to the IRS revealed significant differences between OSCC (mean IRS: 3.5 ) and normal oral samples (mean IRS: 1); $p=0.003$. Scale bar $=100 \mu \mathrm{m}$. 
Table 1. Stained TMAs were evaluated for SPHK1 staining rates as described in the Methods section

\begin{tabular}{lrrr}
\hline & $\begin{array}{l}\text { Total } \\
\text { cases }\end{array}$ & $\begin{array}{l}\text { Positive } \\
\text { SPHK1 }\end{array}$ & $\begin{array}{l}\text { Negative } \\
\text { SPHK1 }\end{array}$ \\
\hline SCC & & & \\
$\quad$ OSCC & 153 & $113(74 \%)$ & $40(26 \%)$ \\
$\quad$ Extraoral SCC & 93 & $64(69 \%)$ & $29(31 \%)$ \\
$\begin{array}{l}\text { Nonmalignant tissues } \\
\quad \text { Oral tissues } \\
\quad \text { Other tissues }\end{array}$ & 13 & $3(23 \%)$ & $10(77 \%)$ \\
\hline
\end{tabular}

Scores obtained for OSCCs, extraoral squamous cell carcinomas (pharynx, larynx and other locations), nonmalignant oral tissues and various other normal tissues (other tissues) are shown. SCC = Squamous cell carcinoma.

gingiva $(n=1)$ and floor of the mouth $(n=5)$. Also, several cores of nonmalignant tissues (other tissues) served as controls. SPHK1 was expressed at various levels by the tumors examined (representative selected array cores are shown in fig. 2a). The SPHK1 immunoreactivity scores for normal oral sections and for OSCC ranged from 0 to 5 (mean IRS: 1) and from 0 to 9 (mean IRS: 3.5), respectively, as shown in the dot plot graph in figure $2 \mathrm{~b}$. The SPHK1 expression levels were significantly higher in OSCCs compared with normal oral tissue ( $\mathrm{p}=0.003)$. The rate of SPHK1-positive samples (IRS $>0$ ) was 113 of 153 (74\%) in OSCCs and 3 of 13 (23\%) in nonmalignant oral tissues (table 1). Extraoral HNSCC cores showed similar SPHK1-positive staining rates (69\%) as OSCCs. Also, normal tissues belonging to various organs (table 1 : other tissues) exhibited a positive expression frequency (25\%) similar to that of normal oral tissue. Additionally, a correlation between immunohistochemical staining in HNSCC cores and a number of clinical pathological parameters was examined (table 2). These included histological grade, tumor location, patient's country of origin and gender. There were no statistically significant correlations between SPHK1 expression and histological grade $(\mathrm{p}=0.96)$, gender $(\mathrm{p}=0.23)$, primary tumor sites $(\mathrm{p}=$ $0.32)$ or country of origin $(\mathrm{p}=0.10)$.

We also analyzed if there was a correlation between p53 staining, a well-known negative prognostic marker in HNSCC, and SPHK1 expression. There was no correlation between SPHK1 expression and $\mathrm{p} 53$ positivity $(\mathrm{p}=$ 0.07). Significant correlation coefficients were obtained, however, when analyzing the relationship between loss of $\mathrm{p} 21$ expression and SPHK1 positivity $(\mathrm{p}=0.005)$.
Table 2. Correlation of SPHK1 expression with clinical pathological features and country of origin

\begin{tabular}{|c|c|c|c|c|c|}
\hline Characteristic & $\begin{array}{l}\text { Patients } \\
(\mathrm{n}=246)\end{array}$ & $\begin{array}{l}\text { SPHK1 } \\
\text { negative }\end{array}$ & $\begin{array}{l}\text { SPHK1 } \\
\text { low } \\
\text { positive }\end{array}$ & $\begin{array}{l}\text { SPHK1 } \\
\text { high } \\
\text { positive }\end{array}$ & $\mathrm{p}$ \\
\hline \multicolumn{6}{|l|}{ Sex } \\
\hline Male & 97 & 45 & 33 & 19 & \multirow[t]{3}{*}{0.23} \\
\hline Female & 56 & 28 & 14 & 14 & \\
\hline NS & 93 & 40 & 38 & 15 & \\
\hline \multicolumn{6}{|l|}{ Country of origin } \\
\hline Argentina & 37 & 17 & 14 & 6 & \multirow[t]{8}{*}{0.10} \\
\hline Mexico & 8 & 2 & 4 & 2 & \\
\hline USA & 59 & 30 & 17 & 12 & \\
\hline South Africa & 35 & 14 & 12 & 9 & \\
\hline China & 35 & 12 & 13 & 10 & \\
\hline Japan & 15 & 8 & 4 & 3 & \\
\hline India & 9 & 2 & 4 & 3 & \\
\hline Thailand & 48 & 28 & 17 & 3 & \\
\hline \multicolumn{6}{|l|}{ Primary tumor site } \\
\hline Oral cavity & 153 & 80 & 55 & 18 & \multirow[t]{4}{*}{0.32} \\
\hline Pharynx & 10 & 4 & 2 & 4 & \\
\hline Larynx & 12 & 3 & 4 & 5 & \\
\hline Other locations & 71 & 26 & 24 & 21 & \\
\hline \multicolumn{6}{|l|}{ Histological grade } \\
\hline WD & 63 & 28 & 20 & 15 & \multirow[t]{4}{*}{0.96} \\
\hline $\mathrm{MD}$ & 113 & 56 & 40 & 17 & \\
\hline $\mathrm{PD}$ & 64 & 26 & 23 & 15 & \\
\hline NS & 6 & 3 & 2 & 1 & \\
\hline
\end{tabular}

SPHK1 protein expression, as assessed by IHC on the HNSCC tissue microarrays, was not significantly correlated with a number of clinical pathological features, such as gender, tumor location, histological grade and country of origin. NS = Not specified; $\mathrm{WD}=$ well differentiated; $\mathrm{MD}=$ moderately differentiated; $\mathrm{PD}=$ poorly differentiated.

\section{SPHK1 mRNA in Laser Capture-Microdissected Samples}

To confirm the presence of SPHK1 in malignant epithelia within the squamous cell carcinoma specimens, we combined the isolation and extraction of tissues from histologically resolved areas of the tumor by LCM with the quantification of SPHK1 mRNA by qRT-PCR. Cryostat sections of OSCC specimens were briefly stained with hematoxylin, as indicated in Methods, and subjected to LCM. For each case, tumor cell nests and adjacent nonmalignant epithelia were isolated. The material was subjected to isolation of RNA and amplification, followed by SPHK1 mRNA quantitation by qRT-PCR. Using this procedure, SPHK1 was readily detectable in all 4 microdissected tumor samples, thus confirming SPHK1 gene ex- 


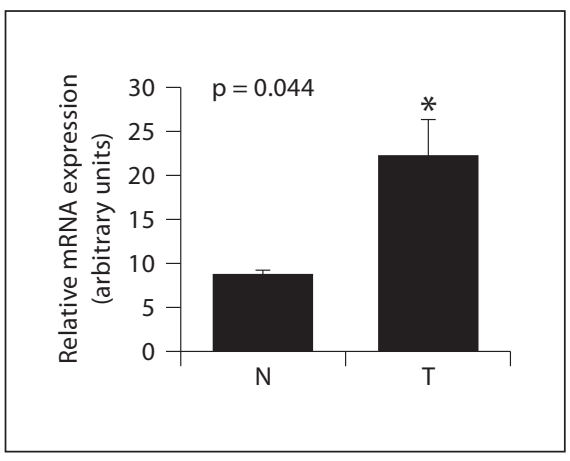

Fig. 3. SPHK1 mRNA expression in OSCC patients. Total RNA was prepared from cancerous or non-malignant epithelial tissues obtained by LCM of samples belonging to 4 OSCC patients, reverse-transcribed and subjected to qRT-PCR using oligonucleotide primers specific for SPHK1. Expression was normalized using HPRT expression as an internal standard. Relative means \pm SEM from SPHK1 mRNA obtained from patients' tumor tissues $(\mathrm{T})$ and normal adjacent tissues $(\mathrm{N})$ are shown $(\mathrm{p}=0.044)$.

pression in tumor epithelia from OSCC patients. As shown in figure 3, mean SPHK1 mRNA levels were increased in tumor epithelial cells when compared with adjacent normal tissue $(\mathrm{p}=0.044)$.

\section{SPHK1 Positivity Correlates with Patient Survival}

SPHK1 affects the 'sphingolipid rheostat,' which likely balances between apoptosis-inducing ceramide and proliferation-stimulating S1P; thus, SPHK1 expression levels may be important to predict a patient's response to therapy. To analyze the prognostic significance of SPHK1 in HNSCC, we selected a cohort of 21 stage III SCC tumors from the oral cavity of male patients who received the same treatment after surgery and performed a KaplanMeier analysis of overall survival according to the expression of SPHK1. Interestingly, positive SPHK1 expression was associated with shorter survival time (log rank test; $\mathrm{p}=0.001)$ as shown in figure 4 .

\section{Discussion}

The 5-year survival rate of patients with advanced HNSCC (50\%) has improved only marginally over the past 3 decades [Jemal et al., 2004] and, in this regard, ongoing efforts aimed at elucidating how the deregulation of molecules contributes to HNSCC progression may help identify new prognostic markers for early diagnosis or response to treatment. On the other hand, many re-

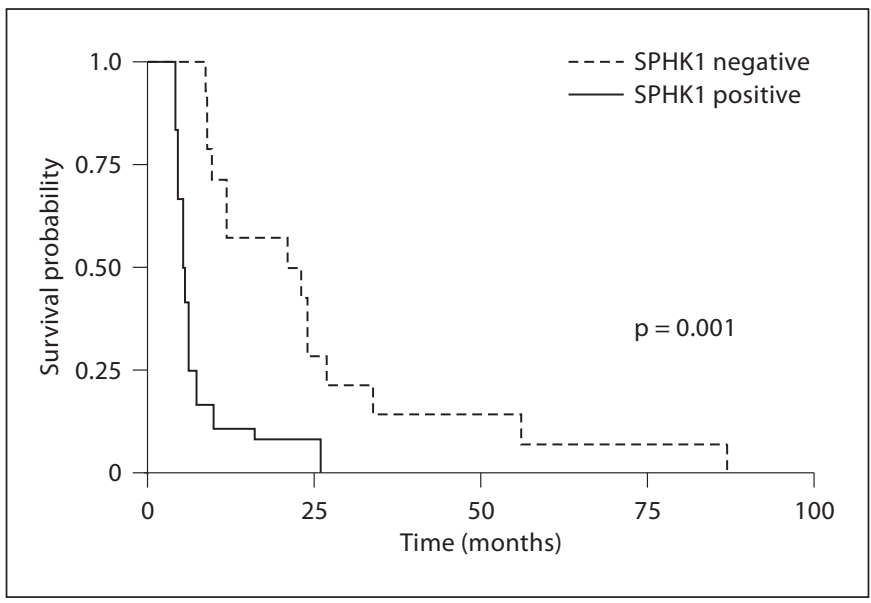

Fig. 4. Correlation of SPHK1 expression with patients' survival time in OSCC. Tumor sections of a subgroup of stage III male oral cancer patients $(n=22)$ were divided into SPHK1 positive (SPHK1+: IRS >0) and SPHK1 negative (SPHK1-: IRS = 0) as determined by immunohistochemical evaluation. SPSS 14.0 was used to perform Kaplan-Meier survival analysis and the log-rank test to determine significance between both survival curves ( $\mathrm{p}=$ $0.001)$.

ports show that SPHK1 is involved in tumorigenesis, and the downregulation of its expression reduces tumor growth, increases apoptosis and enhances chemosensitivity in various types of tumors [Taha et al., 2006; Spiegel and Milstien, 2007].

In this study, we investigated SPHK1 expression in human HNSCC and its relationship with clinical and histopathological features. To our knowledge, this is the first report showing immunolocalization of the SPHK1 protein in tumor sections belonging to HNSCC patients. We demonstrate that SPHK1 is overexpressed in malignant epithelia compared with nonmalignant tissue. We have also shown that SPHK1 expression is correlated with patient survival and with loss of p21 expression but is not associated with other factors, such as gender, p53 expression, histological grade, primary tumor site or patient's country of origin.

Both the immunohistochemical staining and the qRTPCR of SPHK1 in HNSCC specimens showed that SPHK1 expression was stronger in malignant epithelia than in normal oral tissues, which is supported by previous reports showing SPHK1 overexpression in other tumor types [Johnson et al., 2005; French et al., 2006; Kawamori et al., 2006; Ruckhaberle et al., 2007].

We first performed IHC on individual paraffin-embedded tissue sections of HNSCC to obtain detailed in- 
formation on the cell type-specific localization of SPHK1 and as a first screening of protein expression. As previously observed for other tissues [Taha et al., 2006], SPHK1 was mainly found in the cytoplasm of epithelial cells with very low expression levels in stromal cells.

To widely screen for SPHK1 expression, IHC was performed in a HNSCC TMA containing tumor samples from patients representing a variety of countries. Thus, it was clearly a representative screening of SPHK1 expression in HNSCC patients from around the world. In this regard, we did not find significant differences in SPHK1 expression among the patients' various countries of origin.

The relationship between p53, a key regulator of apoptosis, and sphingolipid metabolism is not yet clear. However, the worse prognosis of patients with high p53 expression (associated with mutant p53) might be linked to an upregulation of SPHK1 [Taha et al., 2004], so we studied whether there was a correlation between p53 and SPHK1 levels. We found no significant correlation between the protein levels, which suggests independent mechanisms leading to tumor progression for both proteins. Interestingly, in the case of p21, we observed a significant correlation of SPHK1 expression with p21 loss in HNSCCs.

This result agrees with previously reported data showing upregulation of p21 in colon cancer cells following SPHK1 silencing [Nemoto et al., 2009]. These results are also in line with those by our group showing an upregulation of p21 by phenoxodiol in HNSCC cell lines [Aguero et al., 2004]. Gamble et al. [2006] demonstrated that phenoxodiol inhibits SPHK1, although a direct effect of the drug on SPHK1 activity has never been shown. Phenoxodiol has also been demonstrated to modulate NADH oxidase [Davies et al., 2006; Herst et al., 2007; Morré et al., 2007], Akt [Kamsteeg et al., 2003], topoisomerases or protein tyrosine kinases [Heck et al., 1986; Markovits et al., 1989; Schweigerer et al., 1992].

The existing literature presents controversial results of clinical outcomes in HNSCC that depend on the extent of p21 expression [Miracca et al., 1999; Kapranos et al., 2001; Xie et al., 2002; Li et al., 2003]. Fillies et al. [2007] investigated p21 expression by means of TMAs and showed poor clinical outcomes for p21-negative squamous cell carcinoma of the oral cavity.

High variability in SPHK1 expression among the tumors was observed, which led us to study whether there was a correlation between SPHK1 expression levels and patient survival. Interestingly, survival analysis revealed a worse outcome in patients with positive SPHK1 expres- sion (fig. 4). This finding agrees with similar studies performed in glioblastoma [Van Brocklyn et al., 2005] and breast cancer patients [Ruckhaberle et al., 2007] that showed a correlation between SPHK1 expression and patient survival time. Moreover, they did not observe higher expression of SPHK1 in glioblastomas (grade 4) compared with pilocytic astrocytomas (grade 1), although they found a clear correlation between SPHK1 expression and overall patient survival. Similar to our studies, they also observed high variability in SPHK1 expression among tumors. The correlation between SPHK1 expression and poor prognosis is related to the antiapoptotic and proliferative properties of its lipid product S1P as well as its role in cell migration and invasion [Miller et al., 2008]. Furthermore, several reports show that SPHK1 expression is important to predicting a patient's response to therapy in various cancer types [Shida et al., 2008]. Contradictory results have been observed when studying the effects of S1P in keratinocytes; some reports show cytoprotective effects on this cell type [Manggau et al., 2001], whereas others show anti-proliferative and prodifferentiating activity [Vogler et al., 2003; Herzinger et al., 2007]. Our results support a cytoprotective effect of S1P on HNSCC epithelial cells, an effect which might lead to a more agressive phenotype. Another possible explanation for the worse prognosis of patients with HNSCC tumors expressing SPHK1 could be that the resulting elevated levels of S1P or reduced levels of ceramide lead to resistance to therapy [Higo et al., 2006]. Ceramide, a key lipid in the sphingolipid pathway, can accumulate following the exposure of cells to various DNA-damaging therapeutic agents [Radin et al., 2003]. However, high SPHK1 expression could lead to reduced ceramide levels, thus abrogating apoptosis. Furthermore, previous reports indicating that ceramide induces apoptosis in a human squamous carcinoma cell line [Sugiki et al., 2000] and in a keratinocyte cell line [Bektas et al., 2000] also support the association of SPHK1 expression with poor prognosis in HNSCC tumors. Additionally, it was recently demonstrated that ceramide metabolism is correlated with lymphovascular invasion and nodal metastasis in HNSCC [Karahataya et al., 2007]. Karahataya et al. [2007] showed that $\mathrm{C}_{18}$-ceramide was decreased in tumor tissue compared with normal tissue. It may be possible that, in HNSCC, increased SPHK1 levels result in reduced concentrations of some ceramide species within the tumor microenvironment, thus favoring tumor progression.

Our results suggest that SPHK1 expression could be of potential interest as a prognostic marker in HNSCC, and 
future studies should address the issue of whether inhibiting this protein induces a better response to therapy. Further studies should be performed to gain a better understanding of the role of SPHK1 in HNSCC.

\section{Acknowledgements}

This work was supported by grants from the Scientific Commission of Buenos Aires Province (CIC) and from the Secretary of Science and Technology of the Universidad Nacional del Sur. M.E.F. is the recipient of a fellowship from the CIC and A.G. from the CONICET. We thank Dr. Lina M. Obeid for generously sharing the polyclonal SPHK1 antibody with us.

\section{References}

Aguero, M.F., M.M. Facchinetti, Z. Sheleg, A.M. Senderowicz (2005) Phenoxodiol, a novel isoflavone, induces G1 arrest by specific loss in cyclin-dependent kinase 2 activity by $\mathrm{p} 53$ independent induction of p21WAF1/CIP1. Cancer Res 65: 3364-3373

Alvarez, S.E., S. Milstien, S. Spiegel (2007) Autocrine and paracrine roles of sphingosine-1phosphate. Trends Endocrinol Metab 18: 300-307.

Bektas, M., C.E. Orfanos, C.C. Geilen (2000) Different vitamin D analogues induce sphingomyelin hydrolysis and apoptosis in the human keratinocyte cell line $\mathrm{HaCaT}$. Cell Mol Biol (Noisy-le-grand) 46: 111-119.

Bukholm, I.K., J.M. Nesland, R. Karesen, U. Jacobsen, A.L. Borresen-Dale (1997) Interaction between bcl-2 and p21 (WAF1/CIP1) in breast carcinomas with wild type p53. Int J Cancer 73: 38-41

Davies, S.L., J. Bozzo (2006) Spotlight on tNOX: a tumor-selective target for cancer therapies. Drug News Perspect 19: 223-225.

Facchinetti, M.M., A. De Siervi, D. Toskos, A.M Senderowicz (2004) UCN-01-induced cell cycle arrest requires the transcriptional induction of $\mathrm{p} 21$ (waf1/cip1) by activation of mitogen-activated protein/extracellular signal-regulated kinase kinase/extracellular signal-regulated kinase pathway. Cancer Res 64: 3629-3637.

Facchinetti, M.M., F. Leocata Nieto, M.G. Márquez, N. Sterin-Speziale (2008) Stratification of sphingosine kinase-1 expression and activity in rat kidney. Cells Tissues Organs 188: 388-392.

Fillies, T., M. Woltering, B. Brandt, J.P. Van Diest, R. Werkmeister, U. Joos, H. Buerger (2007) Cell cycle regulating proteins p21 and p27 in prognosis of oral squamous cell carcinomas. Oncol Rep 17: 355-359.

French, K.J., J.J. Upson, S.N. Keller, Y. Zhuang, J.K. Yun, C.D. Smith (2006) Antitumor activity of sphingosine kinase inhibitors. J Pharmacol Exp Ther 318: 596-603.

Futerman, A.H., Y.A. Hannun (2004) The complex life of simple sphingolipids. EMBO Rep 5: 777-782.
Gamble, J.R., P. Xia, C.N. Hahn, J.J. Drew, C.J. Drogemuller, D. Brown, M.A. Vadas (2006) Phenoxodiol, an experimental anticancer drug, shows potent antiangiogenic properties in addition to its antitumor effects. Int J Cancer 118: 2412-2420.

Gorgoulis, V., V. Zoumpourlis, G. Rassidakis, A. Karameris, C. Barbatis, D.A. Spandidos, C. Kittas (1995) Molecular analysis of p53 gene in laryngeal premalignant and malignant lesions. $\mathrm{p} 53$ protein immunohistochemical expression is positively related to proliferating cell nuclear antigen labelling index. Virchows Arch 426: 339-344.

Greene, F.L., D.L. Page, I.D. Fleming, A. Fritz, C.M. Balch (2002) AJCC Cancer Staging Manual, ed 6. New York, Springer.

Hait, N.C., C.A. Oskeritzian, S.W. Paugh, S. Milstien, S. Spiegel (2006) Sphingosine kinases, sphingosine 1-phosphate, apoptosis and diseases. Biochim Biophys Acta 1758: 2016 2026.

Hait, N.C., J. Allegood, M. Maceyka, G.M. Strub, K.B. Harikumar, S.K. Singh, C. Luo, R. Marmorstein, T. Kordula, S. Milstien, S. Spiegel (2009) Regulation of histone acetylation in the nucleus by sphingosine-1-phosphate. Science 325: 1254-1257.

Hammer, S., B. Sauer, I. Spika, C. Schraut, B. Kleuser, M. Schafer-Korting (2004) Glucocorticoids mediate differential anti-apoptotic effects in human fibroblast and keratinocytes via sphingosine-1-phosphate formation. J Cell Biochem 91: 840-851.

Hannun, Y.A., L.M. Obeid (2008) Principles of bioactive lipid signalling: lessons from sphingolipids. Nat Rev Mol Cell Biol 9: 139150.

Heck, M.M., W.C. Earnshaw (1986) Topoisomerase II: a specific marker for cell proliferation. J Cell Biol 103: 2569-2581.

Herst, P.M., T. Petersen, P. Jerram, J. Baty, M.V. Berridge (2007) The antiproliferative effects of phenoxodiol are associated with inhibition of plasma membrane electron transport in tumour cell lines and primary immune cells. Biochem Pharmacol 74:15871595.

-Herzinger, T., B. Kleuser, M. Schäfer-Korting, H.C. Korting (2007) Sphingosine-1-phosphate signaling and the skin. Am J Clin Dermatol 8: 329-336.
Higo, M., K. Uzawa, T. Kawata, Y. Kato, Y. Kouzu, N. Yamamoto, T. Shibahara, J.E. Mizoe, H. Ito, H. Tsujii, H. Tanzawa (2006) Enhancement of SPHK1 in vitro by carbon ion irradiation in oral squamous cell carcinoma. Int J Radiat Oncol Biol Phys 65: 867-875

Hla, T. (2003) Signaling and biological actions of sphingosine 1-phosphate. Pharmacol Res 47: 401-407.

Hong, J.H., J.K. Youm, M.J. Kwon, B.D. Park, Y.M. Lee, S.I. Lee, D.M. Shin, S.H. Lee (2008) K6PC-5, a direct activator of sphingosinekinase 1, promotes epidermal differentiation through intracellular $\mathrm{Ca}^{2+}$ signaling. J Invest Dermatol 128: 2166-2178.

-Igarashi, N., T. Okada, S. Hayashi, T. Fujita, S. Jahangeer, S. Nakamura (2003) Sphingosine kinase 2 is a nuclear protein and inhibits DNA synthesis. J Biol Chem 278: 46832 46839.

Jemal, A., L.X. Clegg, E. Ward, La Ries, X. Wu, P.M. Jamison, P.A. Wingo, H.L. Howe, R.N. Anderson, B.K. Edwards (2004) Annual report to the nation on the status of cancer, 1975-2001, with a special feature regarding survival. Cancer 101: 3-27.

-Jemal, A., R. Siegel, E. Ward (2007) Cancer statistics. CA Cancer J Clin 57: 43-66.

Johnson, K.R., K.P. Becker, M.M. Facchinetti, Y.A. Hannun, L.M. Obeid (2002) PKC-dependent activation of sphingosine kinase 1 and translocation to the plasma membrane. Extracellular release of sphingosine-1-phosphate induced by phorbol 12-myristate 13-acetate (PMA). J Biol Chem 277: $35257-$ 35262.

Johnson, K.R., K.Y. Johnson, H.G. Crellin, B. Ogretmen, A.M. Boylan, R.A. Harley, L.M. Obeid (2005) Immunohistochemical distribution of sphingosine kinase 1 in normal and tumor lung tissue. J Histochem Cytochem 53: 1159-1166.

Kapranos, N., G.P. Stathopoulos, L. Manolopoulos, et al (2001) p53, p21 and p27 protein expression in head and neck cancer and their prognostic value. Anticancer Res 21: 521528 .

Kamsteeg, M., T. Rutherford, E. Sapi, B. Hanczaruk, S. Shahabi, M. Flick, D. Brown, G. Mor (2003) Phenoxodiol - an isoflavon analogue - induces apoptosis in chemo-resistant ovarian cancer cells. Oncogene 22: 2611-2620. 
Karahataya, S., K. Thomasa, S. Koybasia, C.E. Senkala, S. El Ojeimyc, X. Liu, J. Bielawski, T.A. Day, M.B. Gillespie, D. Sinha, J.S. Norris, Y.A. Hannun, B. Ogretmen (2007) Clinical relevance of ceramide metabolism in the pathogenesis of human head and neck squamous cell carcinoma (HNSCC): attenuation of C18-ceramide in HNSCC tumors correlates with lymphovascular invasion and nodal metastasis. Cancer Lett 256: 101-111.

-Kawamori, T., W. Osta, K.R. Johnson, B.J. Pettus, J. Bielawski, T. Tanaka, M.J. Wargovich, B.S. Reddy, Y.A. Hannun, L.M. Obeid, D. Zhou (2006) Sphingosine kinase 1 is up-regulated in colon carcinogenesis. FASEB J 20: 386388.

Kohama, T., A. Olivera, L. Edsall, M.M. Nagiec, R. Dickson, S. Spiegel (1998) Molecular cloning and functional characterization of murine sphingosine kinase. J Biol Chem 273: 23722-23728.

Kohno, M., M. Momoi, M.I. Oo, J.H. Paik, Y.M. Lee, K. Venkataraman, J. Ai, A.P. Ristimaki, H. Fyrst, H. Sano, D. Rosenberg, J.D. Saba, R.I. Proia, T. Hla (2006) Intracellular role for sphingosine kinase in intestinal adenoma proliferation. Mol Cell Biol 26: 7211-7223.

Li, W., C.H. Thompson, C.J. O’Brien, E.B. McNeil, R.A. Scolyer, Y.E. Cossart, M.J. Veness, D.M. Walker, G.J. Morgan, B.R. Rose (2003) Human papillomavirus positivity predicts favourable outcomefor.squamous carcinoma of the tonsil. Int J Cancer 106: 553-558.

Liu, H., M. Sugiura, V.E. Nava, L.C. Edsall, K. Kono, S. Poulton, S. Milstien, T. Kohama, S. Spiegel (2000) Molecular cloning and functional characterization of a novel mammalian sphingosine kinase type 2 isoform. J Biol Chem 275: 19513-19520.

Liu, H., R.E. Toman, S.K. Goparaju, M. Maceyka, V.E. Nava, H. Sankala, S.G. Payne, M. Bektas, I. Ishii, J. Chun, S. Milstien, S. Spiegel (2003) Sphingosine kinase type 2 is a putative $\mathrm{BH} 3$-only protein that induces apoptosis. J Biol Chem 278: 40330-40336.

-Livak, K.J., T.D. Schmittgen (2001) Analysis of relative gene expression data using real-time quantitative PCR and the $2^{-\Delta \Delta \mathrm{C}_{\mathrm{T}}}$ method. Methods 25: 402-408.

-Manggau, M., D.S. Kim, L. Ruwisch, R. Vogler, H.C. Korting, M. Schäfer-Korting, B. Kleuser (2001) $1 \alpha, 25$-dihydroxyvitamin D3 protects human keratinocytes from apoptosis by the formation of sphingosine-1-phosphate. J Invest Dermatol 117: 1241-1249.

Markovits, J., C. Linassier, P. Fosse, J. Couprie, J. Pierre, A. Jacquemin-Sablon, J.M. Saucier, J.B. Le Pecq, A.K. Larsen (1989) Inhibitory effects of the tyrosine kinase inhibitor genistein on mammalian DNA topoisomerase II. Cancer Res 49: 5111-5117.

Miller, A.V., S.E. Alvarez, S. Spiegel, D.A. Lebman (2008) Sphingosine kinases and sphingosine-1-phosphate are critical for TGF $\beta$-induced ERK1/2 activation and promotion of migration and invasion of esophageal cancer cells. Mol Cell Biol 28: 4142-4151.
Miracca, E.C., L.P. Kowalski, M.A. Nagai (1999) High prevalence of p16 genetic alterations in head and neck tumours. Br J Cancer 81: 677683 ,

Molinolo, A.A., S.M. Hewitt, P. Amornphimoltham, S. Keelawat, S. Rangdaeng, A. Meneses García, A.R. Raimondi, R. Jufe, M. Itoiz, Y. Gao, D. Saranath, G.S. Kaleebi, G.H. Yoo, L. Leak, E.M. Myers, S. Shintani, D. Wong, H.D. Massey, W.A. Yeudall, F. Lonardo, J. Ensley, J.S. Gutkind (2007) Dissecting the Akt/mammalian target of rapamycin signaling network: emerging results from the head and neck cancer tissue array initiative. Clin Cancer Res 13: 4964-4973.

-Morré, D.J., P.J. Chueh, K. Yagiz, A. Balicki, C. Kim, D.M. Morré (2007) ECTO-NOX target for the anticancer isoflavene phenoxodiol. Oncol Res 16: 299-312.

Murate, T., Y. Banno, K. T-Koizumi, K. Watanabe, N. Mori, A. Wada, Y. Igarashi, A. Takagi, T. Kojima, H. Asano, Y. Akao, S. Yoshida, H. Saito, Y. Nozawa (2001) Cell type-specific localization of sphingosine kinase 1a in human tissues. J Histochem Cytochem 49: 845-855.

Nemoto, S., M. Nakamura, Y. Osawa, S. Kono, Y. Itoh, Y. Okano, T. Murate, A. Hara, H. Ueda, Y. Nozawa, Y. Banno (2009) Sphingosine kinase isoforms regulate oxaliplatin sensitivity of human colon cancer cells through ceramide accumulation and Akt activation. J Biol Chem 284: 10422-10432.

Olivera, A., T. Kohama, L. Edsall, V. Nava, O. Cuvillier, S. Poulton, S. Spiegel (1999) Spingosine kinase expression increases intracellular sphingosine-1-phosphate and promotes cell growth and survival. J Cell Biol 147: 545-558.

Pitson, S.M., R.J. D’andrea, L. Vandeleur, P.A. Moretti, P. Xia, J.R. Gamble, M.A. Vadas, B.W. Wattenberg (2000) Human sphingosine kinase: purification, molecular cloning and characterization of the native and recombinant enzymes. Biochem J 350: 429-41.

Radin, N.S (2003) Killing tumours by ceramideinduced apoptosis: a critique of available drugs. Biochem J 371: 243-256.

Ruckhäberle, E., A. Rody, K. Engels, R. Gaetje, G. von Minckwitz, S. Schiffmann, S. Grösch, G. Geisslinger, U. Holtrich, T. Karn, M. Kaufmann (2007) Microarray analysis of altered sphingolipid metabolism reveals prognostic significance of sphingosine kinase 1 in breast cancer. Breast Cancer Res Treat 112: $41-52$.
Sankala, H.M., N.C. Hait, S.W. Paugh, D. Shida, S. Lépine, L.W. Elmore, P. Dent, S. Milstien, S. Spiegel (2007) Involvement of sphingosine kinase 2 in p53-independent induction of p21 by the chemotherapeutic drug doxorubicin. Cancer Res 67: 10466-10474.

-Schüppel, M., U. Kürschner, U. Kleuser, M. Schäfer-Korting, B. Kleuser (2008) Sphingosine 1-phosphate restrains insulin-mediated keratinocyte proliferation via inhibition of Akt through the S1P2 receptor subtype. J Invest Dermatol 128: 1747-1756.

Schweigerer, L., K. Christeleit, G. Fleischmann, H. Adlercreutz, K. Wahala, T. Hase, M. Schwab, R. Ludwig, T. Fotsis (1992) Identification in human urine of a natural growth inhibitor for cells derived from solid pediatric tumors. Eur J Clin Invest 22: 260-264.

Shida, D., K. Takabe, D. Kapitonov, S. Milstien, S. Spiegel (2008) Targeting SphK1 as a new strategy against cancer. Curr Drug Targets 9: 662-673.

-Spiegel, S., S. Milstien (2007) Functions of the multifaceted family of sphingosine kinases and some close relatives. J Biol Chem 282: 2125-2129.

Sugiki, H., Y. Hozumi, H. Maeshima, Y. Katagata, Y. Mitsuhashi, S. Kondo (2000) C2-ceramide induces apoptosis in a human squamous cell carcinoma cell line. Br J Dermatol 143: 1154-1163.

Taha, T.A., W. Osta, L. Kozhaya, J. Bielawski, K.R. Johnson, W.E. Gillanders, G.S. Dbaibo, H.A. Hannun, L.M. Obeid (2004) Down regulation of sphingosine kinase-1 by DNA damage. Dependence on proteases and p53. J Biol Chem 279: 20546-20554.

Taha, T.A., Y.A. Hannun, L.M. Obeid (2006) Sphingosine kinase: biochemical and cellular regulation and role in disease. J Biochem Mol Biol 39: 113-131.

-Vadas, M., P. Xia, G. McCaughan, J. Gamble (2008) The role of sphingosine kinase 1 in cancer: Oncogene or non-oncogene addiction? Biochim Biophys Acta 1781: 442-447.

-Van Brocklyn, J.R., C.A. Jackson, D.K. Pearl, M.S. Kotur, P.J. Snyder, T.W. Prior (2005) Sphingosine kinase-1 expression correlates with poor survival of patients with glioblastoma multiforme: roles of sphingosine kinase isoforms in growth of glioblastoma cell lines. J Neuropathol Exp Neurol 64: 695-705.

-Vogler, R., B. Sauer, D.S. Kim, M. Schäfer-Korting, B. Kleuser (2003) Sphingosine-1-phosphate and its potentially paradoxical effects on critical parameters of cutaneous wound healing. J Invest Dermatol 120: 693-700.

Xia, P., J.R. Gamble, L. Wang, S.M. Pitson, P.A. Moretti, B.W. Wattenberg, R.J. D'Andrea, M.A. Vadas (2000) An oncogenic role of sphingosine kinase. Curr Biol 10: 1527-1530.

Xie, X., O.P. Clausen, M. Boysen (2002) Prognostic significance of p21WAF1/CIP1 expression in tongue squamous cell carcinomas. Arch Otolaryngol Head Neck Surg 128: 897902. 